Observação 1.a). M. L. branca, viuva, multipara, não notificando accidentes venereos em seu passado.

Diagnostico gynecologico: metrite hemorrhagica.

Não sendo encontrado motivo para a metrite, pois não havia informes de abortos recentes, e nem existindo elementos que fizessem viavel a idéa de polypo, prevaleceu a hypothese de metrite por esclerose da mucosa uterina. Os annexos eram inattingiveis ao toque combinado, indolores e, bem assim, o utero.

Tratamento: asseio vaginal por meio de lavagens com solução de acido tannico e bi-borato de sodio e com solução de chloreto de sodio (um dia com cada uma dellas), desinfecção intestinal e injecções de chlorhydrato de emetina a 3 o|o, cada dous dias, sendo injectados seis centigrammos por vez. Depois da 2.a injecção, desappareceram as perdas sanguineas, ficando, porém, um corrimento esbranquiçado, que cedeu, por fim, após 8 injecções do medicamento. O tratamento foi rematado com o emprego do iodeto de potassio e do bi-iodeto de mercurio, em pequenas doses este ultimo, attentas as idiéas modernamente adquiridas sobre as metrites.

Observação 2.a). - A doente a que se refere esta segunda observação era multipara e portadora de uma metrite chronica. Declarou a paciente que, logo após o seu casamento, contraiu vasta infecção, attribuida aos germes de Neisser, e da qual resultou um aborto. Tratou-se longamente.

Perto de 10 annos depois do accidente relatado, fomos chamado (Mello Camargo) para vel-a. O tratamento foi em tudo identico ao 1.0 caso e, como o tratamento, tambem o foi o resultado. Mezes depois de terminado o tratamento, a cura ainda persiste, completa.

Eis assim relatados, ligeiramente, os resultados que o emprego da emetina pode dar no tratamento das metrites, desde que estas não tenham como immediato responsavel o coccus neisseriano.

Com esta nota, concitamos os collegas a novas observações afim cie verificar-se a constancia dos resultados do remedio.

\title{
Contribuição ao estudo sobre a genese dos kystomas simples ovarianos
}

Dr. Carmo Lordy (Preparador contractado de Anatomia Pathologica).

Principalmente entre os auctores allemães muito se tem discutido a respeito da genese dos teratomas e dos teratoides, mais conhecidos sob a denominação de kystos dermoides.

$\mathrm{A}^{\prime}$ theoria de Willms, baseada na partenogenese e posteriormente repudiada pelo mesmo auctor, contrapoz-se a de Marechand-Bonnet, mais logica e convincente.

Salvo pequenas divergencias de interpretação, quasi todos os auctores são de opinião que estas producções tumoriformes pro- 
venham de um blastomero isolado e estacionario durante a evolução do resto do corpo embryonario. Este fragmento, este germe, assim destacado do ovo em via de segmentação terá valores : potenciaes, aptidões em sua differenciação tanto mais pronunciados, quanto mais precoce fôr seu isolamento e inclusão. Assim, remontando-se até a inclusão de cellulas da primeira phase de segmentação do orvo fecundado, com facilidade explica-se a existencia de producções contendo derivados dos 3 folhetos (tridermomas), lembrando a estructura complexa de um embryão.

Ao lado deste germe totipotente, affim da cellula ovo, pode haver outros multipotentes, como os bidermomas, e outros, finalmente, de desenvolvimento unilateral, como os monodermomas.

. Cumpre, entretanto, observar que nem sempre são verificaveis os derivados dos 3 folhetos, podendo acontecer que no desenvolvimento haja prevalecimento de um folheto em detrimento do ou dos outros folhetos, por atrophia, degeneração e successivo desapparecimento. Haja vista o caso apresentado por Saxer, em que á custa dos -3 , folhetos se desenvolveram no ovario apenas alguns dentes, representando um embryoma evoluido unilateralmente. Obedecendo a esta concepção, ultimamente foi-se mais além, até incluir no numero dos teratomas differenciados numa uni'ca direcção os : communs kystomas do ovario.

Tem-se procurado explicar a predilecção da siéde dos teratomas nas glandủaś genitaes de differentes maneíras.

A opinião muito resumida pelo professor Haberfeld é a que mais satisfaz pela clareza e simplicidade. A cellula blastomerica divideze em blastomeros sexuaes, donde provêm as glandulas sexuaes, $\theta$ blastomeros somaticos, de que deriva o resto do organismo. Duas hypotheses se enifrentam, ou fica incluida entre as cellulas sexuaes alguma cellula somatica ou ha entre as cellulas isexuaes alguma com differenciação e potencialidade de uma cellula. somatica. Parece mais verosimil a segunda hypothese, pela muito frequente localização destas producções tumoriformes nas glandulas genitaes.

O resumo destes dados é de grande utilidade para a justa apreciação genetica dos tecídos e orgãos contidos nós kýstos dermoides e porque aproxima da genese destas producções a dos kystomas pluriloculares do ovario, de conformidade com as vistas de Ribbert e de outros auctores:

Um cáso muito instructivo sobre o assumpto tivemos occasião de estudar. Trata-se de uma struma colloide com kysto dermoide de um ovario extirpado, na sua clinica civil, pelo prof: Arnaldo Vieira de Carvalho e enviado ao Laboratorio de Anatomia Pathosogica da Faculdade de Medicina e Cirurgia de S. Paulo.

O exame attencioso da peça, além de suggerir outras apreciações, presta-se para demonstrar a pouca razão que assiste aos que ainda sustentam ser uma pura coincidencia a associação no mesmo tumor do kysto-adenoma com o dermoide.

Como: adiante detalhadamente descrevemos, 'o ponto cephalico, no nosso caso, se acha fora do kysto dermoide, inteiramente com- 
prehendido na massa da struma colloide; o que peremptoriamente comprova a asserção de que o mesmo blastomero incluido e totipotente evoluira produzindo simultaneamente as duas formações.

\section{EXAME MACROSCOPICO}

0 tumor tem $201 \mathrm{~cm}$. de comprimento, $12 \mathrm{~cm}$. de altura e $12 \mathrm{~cm}$. de largura, formando duas partes separadas por um estrangulainento nitido, uma de $113 \mathrm{~cm}$. $\times 1 / 2 \mathrm{~cm}$. $\times 12 \mathrm{~cm}$. e a outra de $7 \mathrm{~cm}$. $\times 10 \mathrm{~cm}$. $\times 8 \mathrm{~cm}$., sendo a maior de superficie nodulosa, com nodulos multiplos salientes e de todos os tamanhos até o de uma nóz, de côr branca acinzentada, havendo muitos de côr azulada. Os nodulos se agglomeram sobretudo numa parte contigua. ao tumor menor, simulando um cacho de uvas.

A outra parte menor tem superficie lisa e côr cinzento-amarellada. Ao corte, a parte maior apresenta o aspecto typico de um kystoadenoma multilocular, com kystos apenas perceptiveis até com 0 tamanho de uma caverna em que caiba uma nóz. $O$ conteudo é de aspecto seroso, outras vezes de colloide e outras tem a côr de chocolate. A consistencia é muito dura, pelo grande numero de largos septos fibrosos entre os diversos kystos. A dureza é ainda maior principalmiente no angulo vizinho das agglomerações kysticas. Neste ponto prevalece a côr vermelha acinzentada com partes brancas de aspectos tendinoso, outra com côr amarellada semelhante a do colioide, com pontinhos mais brancos e consistentes dentro da massa do colloide. O tumor pequeno apresenta ao corte uma massa cholesteriniforme, caracteristica dos dermoides, unctuosa, misturada a grande numero de pellos de tamanho diverso. Tal massa se destaca completamente da membrana que a envolve, dando ao tacto a impressão de pergaminho. $O$ ponto cephalico se encontra na parte do tumor que apresenta o aspecto de kysto-adenoma multilocular.

\section{EXAME MTOROSCOPICO}

Fixação em Müller-formol e Kayserling. Inclusão em paraffina, coloração por hematoxylina-eosina e Van Giesson. Os cortes para exame histologico foram praticados em differentes logares da parte maior e menor do tumor.

As preparações histologicas do kysto dermoide accusavam a existencia de tecidos proprios desta variedade de teratoides, tecido conjuctivo, camada malpighiana, cornea, pellos e massa cholesterinomatosa, que ao esf̣regaço apresentava, além de graxa neutra, grande numero de pequenas taboas de cholesterina, caracteristicam'ente dispostas.

O que prevalecia nas outras preparações correspondentes á parte multiloculada era tecido thyroidiano com a estructura de struma colloide. Havia alveolos de todas as dimensões, cheios de colloide e em cuja massa se encontravam muitas cellulas alveolares descamadas e degeneradas. Como acontece na struma colloide da glanidula thyroide, tambem na ovarica, as cellulas alveolares se apresenta- 


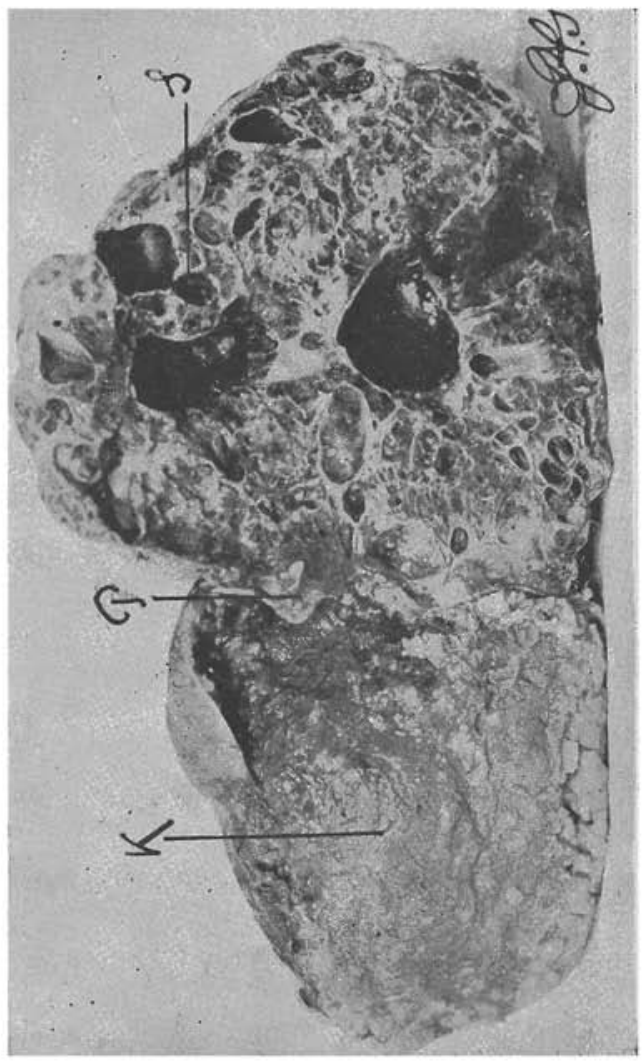

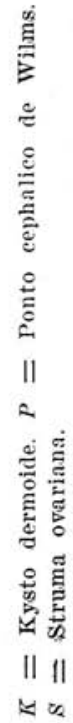



vam de diverso formato, altas, cylindricas, cubicas, chatas, de conformidade com a menor ou maior acção mecanica exercida pela massa, que, neste caso, dava nitidamente a reacção tinctorial da heilkunde.

No tecido conjunctivo mais e menos fibroso, além de diversos pequenos nucleos de cartilagem hyalina, se notavam infiltração parvi-cellular e raros folliculos lymphaticos. Na parte correspondente ao ponto cephalico de Willms, ao lado destes ultimos tecidos observamos uma fileira de cellulas cylindricas ciliadas, separada por tecido conjunctivo de um nucleo eartilaginoso, lembrando a estructura de um esboço de trachéa.

Assim, a 0 s tres casos de struma colloide ovarica de Ribbert. podemos accrescentar o nosso, mais interessisante pela presença do esboço trachéal e do kysto dermoide, evoluindo contemporaneamente c á custa da inclusão muito precoce de um mesmo blastomero totipotente.

\section{BIBLIOGRAPHIA}

Barbacci -- I tumori.

Aschoff - Pathologische Anatomie.

Kauffman. - Trattato di anatomia patologica speciale.

Ribbert. - Geschwulstlehre fur Arzte und Studierend.

Liepmann. - Kurzgefassites Handbuch der gesamtem Frauencolloide.

Borst. - Die Lehre von den Geschwülsten.

\section{Um pouco de chimica}

Domingues de Campos, alumno do 4. ${ }^{\circ}$ anno.

E' uma tendencia do espirito humano, diz Bouty, mudar constantemente o ponto de vista de investigação. Devido a essa inclinacão talvez, feliz ou infelizmente as sciencias avançam em progresso á medida. que crescem em anno. Assim, a Chimica hodierna deixou de ser a sciencia dos sopradores, a sciencia occulta, a sciencia hermetica para se tornar a sciencia das industrias, da medicina, da agricultura, da arte bellica, enfim a sciencia do povo.

Hoje ninguem ignora o valor, a força, o impulso que pode dar a um povo esse ramo do saber humano.

Não precisamos citar exemplos porque elles são por demais numerosos. E, senão volvei os olhos para a Europa e lá encontrareis earos leitores, os povos empenhados na mais titanica das lutas, a 